\title{
Review of Eurasian Steppes. Ecological problems and livelihoods in a changing world, edited by Marinus JA Werger and Marja A van Staalduinen (Springer series: Plant and Vegetation No. 6)
}

\author{
Sarah Robinson
}

\section{Correspondence:}

sarah.robinson09@googlemail.com Imperial College Conservation Science group, Division of Biology, Imperial College London, London, UK

\author{
Book details \\ Werger, Marinus JA; and van Staalduinen, Marja A (editors) \\ Eurasian Steppes. Ecological Problems and Livelihoods in a Changing World. \\ Dordrecht, Heidelberg, New York, London: Springer; 2012. \\ 565 pages, ISBN 978-94-007-3885-0, ISBN 978-94-007-3886-7
}

Keywords: Vegetation, Steppe, Grasslands, Eurasia, Degradation

\section{Review}

Part of the Springer Plant and Vegetation series, this volume covers one of the largest biomes in the world. The book is split into four sections: Steppe Regions, Degradation, Climate Change and Livelihoods. However, as the series title suggests, the main focus is on vegetation. The section on Steppe Regions, which comprises about half of the volume, consists of largely descriptive chapters, each on a different country in which steppe environments are present. These cover temperate continental grasslands from China, Mongolia and Russia, through Kazakhstan to the Ukraine, Anatolia, and parts of Europe including Hungary, Romania, Slovakia and Spain. One of the more confusing aspects of the book is the reference in Chapters 1 and 15 to Central Asia, which is used to mean steppe areas of China including the Tibetan plateau, and Mongolia, and not the five post-Soviet republics usually grouped under this title.

Each of the chapters in the first section presents a classification of steppe vegetation communities, often with very detailed botanical descriptions. Most also discuss vegetation change over time, human impacts and current threats. Some, particularly Chapter 2 on the Russian steppe, provide detailed inventories of protected areas.

Chapter 1 is quite different from the rest of the first section as it is more analytical than descriptive and includes a literature review of the drivers of steppe productivity in Tibet, western China and Mongolia. A meta-analysis of a broad range of grazing studies, including some by the authors themselves, shows how grazing impact varies according to aridity and puts findings in the context of non-equilibrium theory. This is really the only chapter which draws together research findings from different countries 
to enhance our understanding of steppe systems as a whole. Other chapters are more locally specific.

Change is addressed in different ways - for example, Chapter 4 on Turkey presents a systematic botanical approach to describing how vegetation communities change over time under different types of land use, whilst in Chapter 9 on Spain, change is described in a more general and qualitative manner. Of particular interest is Chapter 7 on Hungary in which historical change and the evolution of each vegetation type is reconstructed from eighteenth century literature, whilst detailed maps from recent studies enable the reader to understand how these changes have resulted in current vegetation distributions. In some of the other studies, exhaustive vegetation descriptions are presented without adequate maps. Spatial or temporal narratives, in other words 'stories', which might render the dense botanical information of more interest to the general reader, are a little thin in some cases.

However, in reading these chapters together, a number of common themes emerge. One of these is how much steppe has been lost and how little is protected. With the notable exception of Mongolia, wherever moisture levels permit, steppe ecosystems have been massively converted to cropland - in Europe, only fragments remain. The greatest changes were comparatively recent; many steppes were uninhabited or used only for grazing until the twentieth century; large scale conversion to cropland occurred in the 1950s and 1960s in Kazakhstan and began only in the eighteenth century in Ukraine; half of Turkey's steppe area has been converted to croplands in the last 50 years. The other major threat discussed, which affects the quality of steppe ecosystems rather than their actual existence, is that of overgrazing. This is described as severe in Inner Mongolia and Turkey and has also become an issue in Mongolia where livestock numbers have doubled in recent years. Most chapters also include sections on other factors affecting steppes such as invasive species, afforestation, urbanisation and fire.

Another common theme emerging from the first section is the reduction in human impacts on steppes in the ex-Soviet sphere since 1991. Where this change took the form of abandonment of cropland, such as in Kazakhstan and Russia, it led to regeneration of steppes and increase in their area. Where it took the form of a loss in grazing such as Romania and Slovakia and some parts of Russia, steppe systems were transformed in other ways. The negative effects on steppe ecosystems of total cessation of grazing are emphasised by almost every author, but very different impacts are reported from place to place. We learn that loss of grazing constitutes an existential threat to European steppes, many of which are relics or outlier zones which are quickly invaded by trees once grazing pressure ceases. In other areas, authors emphasise a loss of diversity or productivity through leaf litter accumulation which inhibits grass germination both physically and, as illustrated by experiments described in Chapter 6, by chemical means also. The trend away from steppe cropping in Kazakhstan and Russia may now be moving into reversal in a 'new virgin lands campaign', the sustainability of which is discussed in Chapter 19.

The second section is a selection of chapters grouped under the heading of Degradation, although this is a little artificial as this topic is discussed in all chapters to some extent, and Chapter 1 (which is not in that section) also treats this topic in detail. This section concentrates more on specific local examples or field studies. Chapter 10 describes studies in Mongolia which have identified common patterns of vegetation 
responses to grazing which hold across a number of steppe types and associations. The work was conducted along a railway line from which grazing was excluded for 30 or more years. Chapter 11 attempts to identify groups of plants which might be associated with colonisation of mobile dunes in China and which could thus be useful in their stabilisation. The other two chapters in this section focus on steppe ungulates - namely the Saiga antelope in Kalmykia, where a combination of hunting and habitat destruction have caused near extinction, and the happier story of the successful release of Przewalski's horse in Mongolia.

The section on Climate Change includes three studies on vegetation change in Siberia and one on the relationship between vegetation cover and permafrost decline in Mongolia. In Chapter 14, characterisation of vegetation within relic steppe 'islands' over a humidity and temperature gradient allows the authors to describe the kinds of vegetation changes which might be expected under various climate change scenarios. Ecosystem resilience is the theme of Chapter 15 which describes adaptation to long-term cyclical changes in precipitation; the patterns of extreme fluctuation in plant biomass and mass mortality of vertebrates due to drought, fire and loss of watering areas are surprising to readers such as myself who knows little about Siberia.

The section entitled Livelihoods forms less of a coherent whole than other parts of the book; the discussion of pastoral risk management in Mongolia in Chapters 20 and 21, written by a Mongolian herder, is interesting and also complements nicely some of the climate-related chapters which precede them. The other two papers relate more to government policy but do not really address the interaction between these policies and the steppe users themselves. Chapter 18, which pertains to be on steppe management in China, makes not even passing reference to the large body of literature on the impacts of privatisation and enclosure policies on the steppe environment in Inner Mongolia and other parts of China (for example, see Li et al. 2007; Yan et al. 2005). Chapter 19 provides a novel insight into the ideas and attitudes underlying agricultural Russian policy but could perhaps have provided more detail on why land reform and the market economy have not achieved the ends which the authors propose, namely reducing the cropping of steppes in favour of grazing, which is more sustainable and compatible with conservation of steppe ecosystems. Much has been written on Russian land reform and land abandonment in recent years, and remote sensing studies have also attempted to measure its scale (see Prishchepov et al. 2012 and references therein); again, little of this research is mentioned in the book.

However, we should remember that the book is part of a series on vegetation, and certainly the field botanist or environmental scientist concerned with these steppe ecosystems or interested in their conservation will find a wealth of rich material. As the editors stress in the introduction, most chapters are written by scientists who are from the countries in question and can draw from a wealth of historical literature from nonEnglish sources. The bibliography thus represents an important and useful resource for regional studies on this biome.

Competing interests

The author declares that she has no competing interests. 
References

Li, WJ, SH Ali, and Q Zhang. 2007. Property rights and grassland degradation: a study of the Xilingol Pasture, Inner Mongolia, China. Journal of Environmental Management 85: 461-470.

Prishchepov, AV, D Müller, M Dubinin, M Baumann, and VC Radeloff. 2012. Determinants of agricultural land abandonment in post-Soviet European Russia. Land Use Policy 30: 873-884.

Yan, Z, W Ning, D Yeshi, and J Ru. 2005. A review of rangeland privatisation and its implication in the Tibetan plateau, China. Nomadic Peoples 9(1,2): 31-51.

doi:10.1186/2041-7136-3-2

Cite this article as: Robinson: Review of Eurasian Steppes. Ecological problems and livelihoods in a changing world, edited by Marinus JA Werger and Marja A van Staalduinen (Springer series: Plant and Vegetation No. 6).

Pastoralism: Research, Policy and Practice 2013 3:2

Submit your manuscript to a SpringerOpen ${ }^{\circ}$ journal and benefit from:

- Convenient online submission

- Rigorous peer review

- Immediate publication on acceptance

- Open access: articles freely available online

- High visibility within the field

- Retaining the copyright to your article

Submit your next manuscript at $\gg$ springeropen.com 